\title{
MUDANÇAS CURRICULARES E FORMAÇÃO DOCENTE: DESAFIOS E POSSIBILIDADES
}

\author{
CAMBIOS CURRICULARES Y FORMACIÓN DOCENTE: RETOS Y POSIBILIDADES
}

\author{
CURRICULAR CHANGES AND TEACHER EDUCATION: CHALLENGES AND \\ POSSIBILITIES
}

Jane Mery Richter VOIGT ${ }^{1}$

Sonia Maria Chaves HARACEMIV ${ }^{2}$

Nivia Moreira de CAMARGO ${ }^{3}$

Leiri Aparecida RATTI ${ }^{4}$

RESUMO: Políticas curriculares promovem mudanças nos currículos escolares, na prática e na formação docente. Considerando o contexto social e cultural em que a escola está inserida, os ajustes curriculares devem atender às identidades e características da realidade escolar, exigindo uma construção curricular coletiva e formação permanente do professor. Com base nesse contexto, esta produção tem como objetivo discutir os desafios em relação aos enfrentamentos dos professores diante de novas propostas curriculares prescritas e a formação docente. De perspectiva metodológica qualitativa, a pesquisa apresenta uma discussão teórica sobre conceitos e percepções acerca da formação docente e dos estudos curriculares. Os estudos evidenciam que a possibilidade de avanços na Educação Básica nacional implica investimentos na reorganização da formação de professores, buscando uma residência docente pautada na autonomia curricular, que considere o apoio teórico metodológico aos professores como intelectuais críticos e transformadores, visando à desconstrução/reconstrução de agendas e planejamentos que ressignifiquem a profissionalidade docente.

PALAVRAS-CHAVE: Formação docente. Currículo. Autonomia curricular.

Profissionalidade.

RESUMEN: Las políticas curriculares promueven cambios en los currículos escolares, la práctica y la formación docente. Considerando el contexto social y cultural en el que se inserta la escuela, los ajustes curriculares deben responder a las identidades y características de la realidad escolar, exigiendo una construcción curricular colectiva y una formación docente permanente. Con base en este contexto, esta producción tiene como

\footnotetext{
${ }^{1}$ Universidade da Região de Joinville (UNIVILLE), Joinville - SC - Brasil. Professora Titular e Coordenadora do Programa de Pós-Graduação em Educação. Doutorado em Educação (PUC/SP). ORCID: https://orcid.org/0000-0003-2180-5476. E-mail: jane.mery@univille.br

${ }^{2}$ Universidade Federal do Paraná (UFPR), Curitiba - PR - Brasil. Professora Associada IV no Departamento de Teoria e Prática de Ensino. Doutorado em História e Filosofia da Educação (PUC/SP). ORCID: https://orcid.org/0000-0001-9305-5227. E-mail: sharacemiv@gmail.com

${ }^{3}$ Universidade Federal do Paraná (UFPR), Curitiba - PR - Brasil. Doutoranda no Programa de Pós-Graduação em Educação. ORCID: https://orcid.org/0000-0002-6820-0274. E-mail: nmcamargo@gmail.com

${ }^{4}$ Universidade da Região de Joinville (UNIVILLE), Joinville - SC - Brasil. Mestre em Educação pelo Programa de Pós-Graduação em Educação. Link ORCID: https://orcid.org/0000-0001-8940-9555. E-mail: leiri.r@gmail.com
} 
objetivo discutir los desafios en relación con los enfrentamientos de los docentes ante las nuevas propuestas curriculares prescritas y a la formación docente. Desde una perspectiva metodológica cualitativa, la investigación presenta una discusión teórica que engloba conceptos y percepciones sobre la formación docente y los estudios curriculares. Los estudios muestran que la posibilidad de avances en la Educación Básica nacional implica inversiones en la reorganización de la formación docente, buscando una residencia docente, basada en la autonomía curricular, que considere el apoyo metodológico teórico a los docentes como intelectuales críticos y transformadores, apuntando a la deconstrucción/reconstrucción de agendas y planificación que resignifiquen la profesionalidad del docente.

PALABRAS CLAVE: Formación docente. Currículo. Autonomía curricular. Profesionalismo.

ABSTRACT: The curricular policies promote changes in the school curricula, in practice and in the teacher education. Taking into account the social and cultural context in which the school is put, curricular adjusts must meet the identities and characteristics of such school reality, which requires a collective curricular construction and permanent teacher education. From a qualitative methodological perspective, this research presents a theoretical discussion that encompasses concepts and perceptions about teacher education and curricular studies. Studies show that the possibility of advances in national Basic Education implies investments in the reorganization of teacher education, seeking a teaching residency, based on curricular autonomy, which considers theoretical methodological support to teachers as critical and transforming intellectuals, aiming at the deconstruction/reconstruction of agendas and plannings which resignifies the professionalism of the teacher.

KEYWORDS: Teacher education. Curriculum. Curricular autonomy. Professionalism.

\section{Introdução}

Movimentos globais têm promovido mudanças significativas no currículo da Educação Básica nacional e, consequentemente, nos processos formativos dos professores da escola básica. No ordenamento curricular, tem-se como significação a crítica ao distanciamento entre o currículo da Educação Básica e a formação docente, de modo que nesse âmbito a lacuna que surge nos processos da docência transcende a identificação dos percalços para o ensino e formação dos estudantes pelos professores.

Para pensar a relação entre as propostas curriculares para a Educação Básica e a formação docente, considerando as tensões e os enfrentamentos dos professores diante das mudanças sociais, questões curriculares e metodologias de ensino, surgiram algumas indagações: Qual a autonomia curricular do docente como intelectual crítico e transformador? Como os professores enfrentam os procedimentos referentes à avaliação e à prática docente, 
propostos por órgãos superiores, nas instituições escolares da rede pública? Como se dá o processo de formação de professores diante das mudanças curriculares?

Dessa forma, o objetivo da presente produção é discutir os desafios em relação aos enfrentamentos dos professores diante de novas propostas curriculares prescritas e a formação docente. Para isso, considera-se que as mudanças teórico-metodológicas apresentadas pelas recentes políticas curriculares não podem ser dissociadas da formação, atuação, desenvolvimento profissional docente e do contexto escolar.

Para o estudo e a análise, cabe destacar a importância da função educadora da docência, a ser desenvolvida de forma condizente com a realidade contextual, conforme analisa Arroyo (2013), ao afirmar que o Estado corrobora para que a educação seja direcionada a resultados classificatórios que atendam às demandas de vocação do mercado de trabalho em detrimento aos contextos em que estão inseridos as escolas e os indivíduos, sejam estudantes ou docentes.

Nessa perspectiva, levanta-se a hipótese de que tanto o peso e a valoração sobre os currículos normatizantes como as diretrizes e prescrições ao trabalho docente corroboram com o sentido político de disputa entre o que está proposto e as tensões na apropriação e expropriação do profissional docente em sua prática cotidiana.

Para Nóvoa (2009, p. 27), "a educação vive um tempo de grandes incertezas e de muitas perplexidades. Nessa criticidade, percebe-se a necessidade de mudanças, mas nem sempre conseguimos definir-lhes o rumo". Isso não significa que não houve avanços referentes à realidade da escola atual, todavia as tensões estão expostas, quebrando o ocultamento tão prolongado em monólogos curriculares e reafirmando a necessária articulação entre o currículo e a sala de aula.

O currículo, como campo de disputas no cenário globalizado, contempla escolhas sobre o quê e como será ensinado nas instituições de ensino, como um conjunto de conhecimentos e intenções políticas e culturais, com base em pressupostos econômicos e ideológicos que influenciam na formação dos sujeitos e de certa forma na organização social, conforme afirma Apple (2006). Nesse sentido, considerando o contexto social e cultural em que a escola está inserida, os ajustes do currículo em relação às identidades e características da realidade escolar requisitam uma construção curricular coletiva a ser promovida, segundo Sacristán (1998), na qual as ações docentes possam melhorar a qualidade da prática pedagógica.

Pacheco (2005) define o currículo como conjunto de experiências planificadas no âmbito da escolarização. Para o autor, trata-se de "[...] uma construção ampla de intenções e 
práticas que coexistem de uma forma nem sempre coerente, porque se encontram alicerçadas em conflitos, em função de um projeto de formação pertencente a uma dada organização" (PACHECO, 2005, p. 59).

Neste texto propõe-se discutir, com base em três temas, as implicações da relação entre as propostas curriculares e a formação e o desenvolvimento profissional docente. No primeiro, serão abordados conceitos e percepções acerca da formação do profissional que atua na educação básica. O segundo tema refere-se aos currículos prescritos e à autonomia curricular docente, para a formação por meio da residência docente, no contexto da instituição de ensino, buscando os conceitos teóricos e os encadeamentos do processo de apropriação dos professores sobre a prática curricular. No terceiro tema, pretende-se contemplar a discussão dos desafios da relação entre as propostas curriculares e a formação e o desenvolvimento profissional docente.

\section{A formação do profissional para a Educação Básica}

Novos contextos exigem novos profissionais. No campo educacional não é diferente. No Brasil, diante da diversidade de contextos regionais e locais, Voigt (2019) aponta que a formação de professores nas universidades brasileiras, as condições de trabalho e a valorização da profisssão, instrumentalizadas pelas políticas curriculares nacionais, ainda precisam avançar no sentido de repensar a escola e sua função social no âmbito dos conteúdos. De acordo com a autora, em muitos casos, as situações de precariedade na formação profissional docente e nas condições de trabalho nas escolas são agravadas pelas diferenças nos processos de escolarização, em todas as regiões do Brasil. O atual cenário da Educação Básica nacional apresenta um novo estudante que, se por um lado tem acesso fácil a informações locais e globais, por outro carece de cultura, inclusão digital e conhecimento.

Com relação às tecnologias, tem-se a falsa sensação de conhecimento fácil e rápido, o que, muitas vezes, coloca o professor numa condição de menor importância nesse processo, na sociedade. Outros fatores também influenciam a vida profissional do docente, que "ainda é afetada pelas condições de trabalho, os meios técnicos, o respeito, à remuneração, o prestígio e a atração exercida pela profissão, os quais constituem um conjunto heterogêneo de condições na maioria dos países" (ALVES; ANDRÉ, 2013, s/p).

De acordo com Camargo (2018), é possível (re)significar a formação e o desenvolvimento profissional, como proposta intencional e planejada que visa à mudança requisitada aos profissionais da Educação. Nesse processo, que precisa ser crítico e criativo, 
não se pode olvidar que a formação e o desenvolvimento profissional docente podem ser compreendidos como um movimento construído socialmente, e no âmbito escolar e dos cursos de formação, espaços nos quais são mobilizadas diversas possibilidades de apropriação de conhecimentos e saberes docentes.

Nóvoa (2019) enfatiza a importância da iniciação profissional nas instituições universitárias, nas quais as políticas de formação de professores precisam estar articuladas às ações dos professores da Educação Básica, de forma sólida e equilibrada, para que no desenvolvimento do processo curricular se possibilite a integração das novas necessidades e interesses de crianças e jovens na prática docente.

O autor reforça a importância do coletivo docente, que, de acordo com Voigt (2019, p. 31), resultará em transformações "se os professores, por meio de um trabalho colaborativo, compreenderem, assumirem e acreditarem na potencialidade dos projetos educativos das escolas". A relação entre a qualidade da formação e atuação do professor envolve, conforme Alves e André (2013, s/p), “experiência, características pessoais, engajamento social, compromisso com a emancipação do outro", assim a formação docente contempla a busca pela compreensão do contexto escolar.

Nesse sentido, Nóvoa (2009) aponta para cinco disposições que são essenciais à definição dos professores nos dias de hoje: conhecimento, cultura profissional, tato pedagógico, trabalho em equipe e compromisso social. $\mathrm{O}$ autor defende que a formação docente acontece também na prática no espaço escolar, com outros profissionais da área que, com suas experiências e vivências, contribuem para adquirir e aperfeiçoar a prática no exercício da atividade profissional docente.

Tal vivência estabelece uma relação dialética entre os sujeitos, entre o mundo que os constitui e os meandros de sua subjetividade, quando, ao reconhecer-se como parte do todo social, tornam-se capazes de perceber a necessidade da inovação no ensino, a partir do novo. Esses processos partem dos reflexos em si, da constituição da Perijivânie ${ }^{5}$, expressão de Vigotski (1996 apud MARQUES, 2015) que indica a unidade da personalidade e do meio como figura do desenvolvimento, evidenciando a natureza ativa da experiência.

Em análise acerca da importância da formação docente no lócus da escola, Nóvoa (2009) ressalta alguns pontos-chave com relação à formação do professor, que

[...] ganharia muito se se organizasse, preferentemente, em torno de situações concretas, [...], a importância de um conhecimento que vai para

5 "[...] unidade dos elementos pessoais e ambientais que se realiza em uma série de diversas vivências" (VIGOTSKI, 1996, p. 383 apud Marques, 2015, p. 6779). 
além da teoria e da prática e que reflete sobre o processo histórico da sua constituição, $[\ldots]$ a procura de um conhecimento pertinente, que não é uma mera aplicação prática de uma qualquer teoria, mas que exige sempre um esforço de reelaboração, [...] a importância de conceber a formação de professores num contexto de responsabilidade profissional, sugerindo uma atenção constante à necessidade de mudanças nas rotinas de trabalho, pessoais, coletivas ou organizacionais (NÓVOA, 2009, p. 30).

O autor insiste na importância de haver na formação docente um trabalho de pesquisa desenvolvido e construído com os demais profissionais que atuam na escola. Ele reafirma: “[...] o reforço de processos de formação baseadas na investigação só faz sentido se eles forem construídos dentro da profissão" (NÓVOA, 2009, p. 31). Esse movimento concebe $a$ residência docente, a qual tem sido apontada como a real forma de "integrar alguém dentro de uma profissão, a profissão docente, e não apenas dentro de um conhecimento ou de uma forma de atuar" (NÓVOA, 2019, p. 201).

É possível dizer que a formação docente é um processo em movimento que

[...] centrada na escola envolve todas as estratégias empregadas conjuntamente pelos formadores e pelos professores para dirigir os programas de formação de modo a que respondam às necessidades definidas da escola e para elevar a qualidade do ensino e da aprendizagem em sala de aula e nas escolas (IMBERNÓN, 2011, p. 85).

A residência docente pode promover espaço necessário para o desenvolvimento profissional docente e contribuir para a construção da identidade profissional do professor, que se constitui na relação teoria e prática e também nas interações profissionais (MARCELO, 2009a), em âmbito escolar, especialmente em tempos de novas propostas curriculares, que exigem estudos e adequação dos currículos ao contexto.

Ao considerar que apenas influências externas apresentam fragilidades, se comparadas ao interior do campo profissional docente, o controle imposto pelo poder central, por vezes, tem se colocado como um impedimento para o desenvolvimento profissional, que, de acordo com Marcelo (2009a), enquanto processo, abarca questões contextuais da instituição, em especial na interação com outros profissionais.

O desenvolvimento profissional implica um processo contínuo, individual ou coletivo, de desconstrução e reconstrução de conhecimentos que reverberam em todo o fazer docente na instituição, que também sofre transformação. O espaço coletivo da instituição de ensino, que reúne profissionais de diversas áreas de formação e com ricas experiências singulares, faz do ambiente escolar local de formação e desenvolvimento profissional e pessoal, na construção de conhecimentos e identidades docentes. 
[...] a possibilidade de a escola se (re) afirmar como um espaço de referência social depende, essencialmente, da capacidade de os professores construírem uma verdadeira autonomia curricular, imprescindível para poderem perseguir em melhores condições as finalidades educativas, construção essa que não pode dissociar-se de três componentes que consideramos basilares: a competência profissional, a identidade profissional e a profissionalidade docente (MORGADO, 2011a, p. 795).

Ao reconhecer os professores como profissionais dotados de um conjunto especializado de saberes científicos, pedagógicos e profissionais específicos, há "um dado processo de reconfiguração pedagógica dos conhecimentos provenientes dos vários campos do saber humano" (BOTO, 2018, p. 6). Além disso, a nova realidade educacional que integra no contexto social em mudança, tanto global como local, requer um profisssional com capacidade de (re)construir-se em sua profissão e constituir-se ontologicamente em sua identidade. Todos esses fatores configuram a necessidade de autonomia e cosmopolitismo a ser construído pelo profissional da educação, notadamente o professor.

Ao tratar das mudanças que novos processos de reforma e políticas curriculares geram ao fazer docente, cabe reconhecer que estes se desenvolverão no contexto escolar, no qual se desenvolvem processos de desigualdade e inconsistências sociais, políticas, econômicas e culturais. Hagemeyer (2004, p. 81), ao considerar a formação do professor, alerta que "não é mais possível vê-lo alijado das reflexões sobre o processo político-pedagógico do contexto em que atua, respondendo passivamente a propostas de mudança impostas e não discutidas". Dessa forma, faz-se necessário discutir sobre as políticas e propostas curriculares para a Educação Básica, em meio a currículos prescritos e à necessidade de autonomia curricular do professor.

\section{Currículos prescritos versus autonomia curricular docente}

As políticas curriculares, apresentadas como solução para cada momento de crise na educação escolar, constituem um conjunto de regulações e prescrições que, muitas vezes, suprimem as possibilidades de articular as transformações globais que se impõem às expectativas e às singularidades locais. As mudanças estão imbricadas "nas exigências do contexto atual, nas reformas e prescrições oficiais, que colocam o professor no embate cotidiano da função, frente a dilemas e desafios que demandam novas configurações de trabalho" (HAGEMEYER, 2004, p. 81). 
Nesse sentido, Pacheco (2005) contesta as regulamentações centralizadas e defende políticas curriculares que permitam a construção de um currículo como conjunto de experiências planificadas no âmbito da escolarização, que vincula aprendizagem aos planos de ensino. Ao considerarmos o currículo como práxis, Sacristán (1998) defende que teremos uma função socializadora e cultural da escola por meio de objetivos construídos e propostos coletivamente. Nesse processo, as condições estruturais, de organização da escola e as ideias e concepções dos docentes que nela atuam importam em pensar a educação como um processo de transformação educacional (SACRISTÁN, 1998).

O currículo, objeto de críticas e discussões, constitui um amontoado de incompletudes do qual emergem discussões, tornando-se um campo de disputas nas políticas públicas educacionais (MORGADO, 2000), enquanto a manifestação de projeto de escolarização, estudos e definições curriculares implica um conjunto de decisões com a intenção de melhoria da qualidade escolar.

Um currículo oficial determinado, de caráter fortemente prescritivo, tanto para o professor quanto para o ambiente de trabalho nas escolas, resulta em prejuízos para o desenvolvimento do trabalho docente e para a qualidade da educação, conforme alerta Moreira (1996). O autor refere-se a uma prescrição que vem atrelada à regulação, oriunda de uma lógica neoliberal, cuja consequência é o controle do trabalho pedagógico, por meio de um sistema de avaliação de escolas, incidindo na formação de determinadas identidades sociais e definindo qual conhecimento é construído. Nessa perspectiva, evidencia-se a falta de discussões acerca das desigualdades que a modernização neoliberal provoca: o grande contingente de excluídos com o qual a escola deveria preocupar-se (MOREIRA, 1996), desconsiderando o contexto e as carências da comunidade.

Morgado (2005) advoga que "o ato educativo deve ser, essencialmente, um ato de criação", o que exige flexibilidade e trabalho coletivo. Enquanto um currículo prescrito e estandardizado pode aportar características excruciantes, essa característica de prestação de contas, que chegou ligada à globalização, impõe às escolas que têm menos recursos e turmas com mais alunos menos tempo para o desenvolvimento profissional docente (PACHECO, 2018). O delineamento das estruturas curriculares, que aportam temáticas e características conflitivas, acaba por silenciar a realidade da escola.

Diante desse silenciamento, uma das discussões políticas mais importantes tem sido a da autonomia curricular, pois é vista como "oportunidade de mobilização dos agentes e estruturas locais e de reforço do papel da escola enquanto espaço singular de toda a ação educacional e de (re)construção do próprio currículo" (MORGADO, 2009, p. 433). O 
currículo torna-se uma construção compartilhada, estabelecendo um diálogo entre o local e o global, visto que

[...] falar de autonomia curricular é invocar um currículo construído na base de um diálogo permanente entre os agentes diretamente nele implicados, tendo como referência de construção do conhecimento a realidade que the serve de contexto (MORGADO, 2009, p. 433).

O grande desafio é encontrar um ponto de equilíbrio entre as questões mais significativas do local e do global. É preciso repensar o papel dos professores e da sua formação, pois eles devem ser agentes da construção da mudança. Muitas vezes os professores não se engajam nas reformas curriculares. Isso ocorre porque se insiste

[...] na produção do que designamos como reformas por inclusão teorizadas, legisladas e implementadas por entidades alheias à instituição escolar - quando devia investir-se em reformas por eclosão - isto é, resultantes de uma alteração profunda da fisiologia curricular, do envolvimento e responsabilização dos agentes educativos, em especial dos professores, e da possibilidade das escolas se assumirem como autênticos espaços de reflexão e decisão coletivas (MORGADO, 2009, p. 434, grifos do autor).

Os fatores apontados por Morgado (2009), somados a outros como a falta de formação continuada, de condições de trabalho que atendam às necessidades dos professores e da escola, fazem com que as propostas de mudança não tenham sucesso. A seguir, serão discutidos alguns desafios dos professores em relação à sua profissionalização e às mudanças curriculares.

\section{Os desafios curriculares dos profissionais da Educação Básica}

A (des)construção e a (re)construção curricular envolvem o desenvolvimento de um trabalho docente, num movimento do global para o local, pautado nas proposições curriculares dos órgãos centrais, necessário para implementar um projeto que atenda às demandas das comunidades locais. Tal trabalho tem início na (re)elaboração do projeto político-pedagógico, parâmetro fundamental para a gestão e organização da instituição de ensino que, segundo Voigt (2019), visa inseri-la num projeto mais amplo ou de renovação, por intermédio da participação dos agentes educativos. Entende-se como necessário, inicialmente, voltar o olhar crítico às metas e aos objetivos que se quer estabelecer para a instituição de ensino, para reelaborar coletivamente o projeto político-pedagógico da escola e 
o seu currículo, num processo que estabeleça, por meio de ações democráticas, a participação de todos os agentes: pais, alunos, professores e comunidade (VOIGT, 2019).

A ação do professor perpassa ainda o planejamento e a prática docente. Hagemeyer (2004, p. 83) defende que "não é mais possível pensar as propostas pedagógicas atuais sem a análise do processo da mudança engendrado pelo professor, sob pena de que se constituam em planos sem respostas à sua prática real”. Essa perspectiva pressupõe que os professores precisam de elementos para compreender teorias e concepções em novas propostas curriculares, pois a racionalidade da prática está condicionada às políticas educacionais e diretrizes que modelam os currículos da escola de Educação Básica (SACRISTÁN, 1998).

Esse processo também exige autonomia, que, enfatizada nos discursos das políticas educacionais e curriculares, é "concedida, logo reversível e relativa, pois nenhuma escola se pode autonomizar de forma total e unilateral" (ALVES, 2002, p. 162). A flexibilização e a autonomia abordadas nos currículos prescritos correspondem a uma forma de descentralizar decisões tomadas ao nível das políticas educacionais, o que pode, por meio de uma regulação de viés neoliberal, responsabilizar a escola e os professores pelas reformas que se quer implementar.

No âmbito da formação docente, para atender às mudanças que o atual cenário exige, é imprescindível, portanto, um "processo intencional e planejado de atividades e experiências que possam promover o desenvolvimento profissional dos docentes" (ANDRÉ, 2010, p. 175), a fim de preparar o professor para exercer uma autonomia curricular responsável, com vistas à promoção de um processo de ensino e aprendizagem de qualidade.

Nesse ínterim, o desenvolvimento da autonomia curricular do professor requer, de acordo com Morgado (2011b), boa formação e permanente atualização, recursos necessários à melhoria da qualidade do ensino, condições de trabalho que possibilitem avanços na prática e políticas educativas e curriculares descentralizadoras. Todos os fatores citados implicam um espaço educativo político e pedagógico, palco de discussões, reflexões, negociações, parcerias, participação e decisão curricular, não um mero local de implementação de decisões tomadas pelos órgãos superiores.

Os professores devem se assumir como protagonistas nas discussões acerca do que ensinam, a quem e como devem ensinar. Como intelectuais transformadores (GIROUX, 1997), professores são responsáveis na definição de metas em face das circunstâncias que se apresentam. Para isso, "é de fundamental importância que a formação desse educador leve em consideração os aspectos históricos sociais de nossa sociedade" (HARACEMIV et al., 2019, 
p. 162). É nessa perspectiva que o trabalho do professor resulta em ações de transformação e mudanças para uma educação de qualidade e emancipatória. Ou seja,

[...] uma das tarefas mais nobres dos professores é a de conseguirem que os alunos desenvolvam capacidades autônomas de aprendizagem, o que só é possível se lhes proporcionarem a integração de campos de conhecimento e experiências que permitam aos estudantes uma compreensão mais reflexiva e crítica da realidade em que vivem (MORGADO, 2011b, p. 393).

Diante das tensões e com base em Haracemiv et al. (2019), o desafio perante a diversidade tangencia então o questionamento: Considerando a realidade da educação brasileira, como realizar o trabalho docente quando se tem em uma única sala de aula estudantes de diferentes faixas etárias, de culturas e classes sociais distintas, sujeitos de diferentes realidades e vivências? Esse questionamento nos leva a inferir que o desafio do professor e da sua formação ante as mudanças curriculares passa por trazer os sujeitos para os currículos, de forma a mediar o ensinar e aprender a partir das experiências por eles vivenciadas. Assim, num diálogo constante, é possível buscar os significados necessários à formação profissional docente, imprescindível ao processo curricular em mudança.

\section{Considerações finais}

Os questionamentos relacionados à formação do professor, os processos da formação docente e os impedimentos causados por currículos prescritos trazem dilemas que exigem do profissional que ingressa ou daquele com experiência profissional que venha a identificar e ocupar espaços que lhe permitam fazer escolhas.

Os desafios da formação e do desenvolvimento profissional docente hoje decorrem especialmente de recentes políticas curriculares, que, embora se apresentem como descentralizadas, estão carregadas de regulação, seja na prática diária ou ainda por intermédio de testes externos ou avaliações em larga escala, impostas por organismos nacionais e internacionais.

As mudanças sociais e culturais da sociedade atual, em meio às exigências das tecnologias digitais, requerem um novo projeto político-pedagógico nas escolas de Educação Básica; ao professor cabe rever seu planejamento para o desenvolvimento de novas metodologias e práticas pedagógicas. Para que esses momentos possam mobilizar uma atuação docente voltada às reflexões do professor como intelectual transformador, os processos da formação e desenvolvimento profissional docente estão imbricados aos desafios de (des)construir e (re)construir os objetivos do ensino e as novas formas do fazer docente. 
Nesse caso, pode-se falar em (des)considerar as formas tradicionais de ensino, para retomar os questionamentos da pesquisa para as novas formas de mediar e desenvolver o trabalho pedagógico. Esses novos conhecimentos reiteram a possibilidade de desenvolver a autonomia curricular docente, a ser considerada como a possibilidade dos professores de tomar decisões no processo curricular. Na revisão do trabalho curricular, estão incluídas as novas culturas dos estudantes, a inclusão digital, as singularidades locais e a inserção de novas temáticas imprescindíveis para a plena formação e desenvolvimento profissional do professor da escola básica (MORGADO, 2004).

Os movimentos da prática e da formação docente estão interligados aos desafios que decorrem especialmente das mudanças sociais e culturais contemporâneas, que se materializam em novas políticas curriculares, indicando novas análises, mediações e domínios do processo curricular nas áreas de atuação. Tais constatações levam a promover novas formas de (re)construção da formação e do desenvolvimento profissional docente.

Percebe-se que os desafios em relação às propostas curriculares e à formação e ao desenvolvimento profissional docente estão vinculados aos contextos regulatórios, à adequação às mudanças contemporâneas, à inclusão digital, às novas metodologias e novas identidades profissionais. Portanto, percebe-se a necessidade de desconstrução de formas hegemônicas e homogeneizantes da prática curricular, reconstruindo possibilidades de relacionar os avanços que exige a ação curricular à constituição da identidade profissional e à construção da autonomia curricular docente. A ideia é possibilitar, de forma urgente, que os docentes ocupem seus lugares, tomando consciência de sua identidade, para alargar suas fronteiras profissionais de forma autônoma, plural e coletiva.

Diante dessas considerações, a possibilidade de avanços na Educação Básica nacional implica investimentos na reorganização da formação de professores, buscando uma residência docente, pautada em princípios de autonomia curricular, que considere o apoio teóricometodológico aos professores como intelectuais críticos e transformadores, visando à desconstrução/reconstrução de agendas e planejamentos que ressignifiquem a profissionalidade (ou identidade profissional) docente.

\section{REFERÊNCIAS}

ALVES, P. Autonomia curricular: a face oculta da (re) centralização? In: COLÓQUIO SOBRE QUESTÕES CURRICULARES, 5.; COLÓQUIO LUSO-BRASILEIRO, 1., 2002, Braga. Anais [...]. Braga, Portugal, 2002. p. 161-166. 
ALVES, C. S., ANDRÉ, M. E. D. A. A constituição da profissionalidade docente: os efeitos do campo de tensão do contexto escolar sobre os professores. In: REUNIÃO NACIONAL DA ANPED, 36., 2013, Goiânia. Anais [...]. Goiânia: Universidade Federal de Goiás, 2013.

ANDRÉ, M. Formação de professores: a constituição de um campo de estudos. Educação, v. 33, n. 3, p. 174-181, 2010.

APPLE, M. Ideologia e poder. Porto Alegre: Artmed, 2006.

ARROYO, M. G. Currículo, território em disputa. 5. ed. Petrópolis: Vozes, 2013.

BOTO, C. António Nóvoa: uma vida para a educação. Revista Educação e Pesquisa, v. 44, 2018.DOI: http://dx.doi.org/10.1590/s1678-4634201844002003

CAMARGO, N. M. Formação docente e o Ensino Médio a distância na educação de jovens e adultos. 2018. 122 f. Dissertação (Mestrado em Educação) - Universidade Federal do Paraná, Curitiba, 2018.

GIROUX, H. Os professores como intelectuais. Porto Alegre: Artes Médicas, 1997.

HAGEMEYER, R. C. de C. Dilemas e desafios da função docente na sociedade atual: os sentidos da mudança. Educar, n. 24, p. 67-85, 2004. DOI: http://dx.doi.org/10.1590/01044060.350

HARACEMIV, S. M. C.; SOEK, A. M.; MILEK, E. Diversidade e multiculturalismo: formação docente necessária à educação de jovens e adultos. Dialogia, n. 31, p. 155-164, 2019. Disponível em: https://doi.org/10.5585/dialogia.N31.8675

IMBERNÓN, F. Formação docente e profissional, formar-se para a mudança e a incerteza. 9. ed. São Paulo: Cortez, 2011.

MARCELO, C. Desenvolvimento profissional docente: passado e futuro. Sisifo - Revista de Ciência da Educação, n. 8, p. 7-22, 2009a.

MARCELO, C. Identidade docente: constantes e desafios. Formação Docente. Revista Brasileira de Pesquisa Sobre Formação Docente, v. 1, n.1, p. 95-108, 2009 b.

MARQUES, E. de S. A. Perijivânie (vivência), afetos e sentidos na obra de Vigotski e na pesquisa em educação. In: CONGRESSO NACIONAL DE EDUCAÇÃO, 12., 2015, Curitiba. Anais [...]. Curitiba, PR: Pontifícia Universidade Católica do Paraná, 2015. p. 67746787.

MOREIRA, A. F. B. Os parâmetros curriculares nacionais em questão. Educação \& Realidade, v. 21, n. 1, p. 9-22, 1996.

MORGADO, J. C. A (des)construção da autonomia curricular. Porto: Edições ASA, 2000.

MORGADO, J. C. Currículo e profissionalidade docente. Porto: Porto, 2005. 
MORGADO, J. C. Identidade e profissionalidade docente: sentidos e (im) possibilidades. Ensaio: Avaliação e Políticas Públicas em Educação, v. 19, n. 73, p. 793-812, 2011 a.

MORGADO, J. C. Lideranças e autonomia: impactos na mudança das práticas curriculares. Revista Contrapontos, v. 4, n. 3, p. 425-438, 2009.

MORGADO, J. C. Liderança e autonomia: impactos na mudança das práticas curriculares. Contrapontos, v. 4, n. 3, p. 425-438, 2004.

MORGADO, J. C. Projecto curricular e autonomia da escola: das intenções às práticas. Revista Brasileira de Política e Administração da Educação, v. 27, n. 3, p. 361-588, 2011b. DOI: https://doi.org/10.21573/vol27n32011.26411

NÓVOA, A. Entre a formação e a profissão: ensaio sobre o modo como nos tornamos professores. Currículo Sem Fronteiras, v. 19, n. 1, p 198-208, 2019.

NÓVOA, A. Para uma formação de professores construída dentro da profissão. In: NÓVOA, A. Professores: imagens do futuro presente. Lisboa: Educa, 2009

PACHECO, J. A. Estudos curriculares para compreensão crítica da educação. Porto: Porto, 2005.

PACHECO, J. A. Ser professor em contextos de regulação transnacional. Para uma atitude cosmopolita docente. CIEd-IE, Universidade do Minho, Portugal, 2018.

SACRISTÁN, J. G. O currículo: uma reflexão sobre a prática. 3. ed. Porto Alegre: Artmed, 1998.

VEIGA, I. P. A. Projeto político-pedagógico da escola: uma construção coletiva. In: VEIGA, I. P. A. (Org.). Projeto político-pedagógico da escola: uma construção possível. Campinas: Papirus, 2002. p. 11-35.

VOIGT, J. M. R. O projeto político-pedagógico da escola brasileira e a construção da autonomia curricular: possibilidades e desafios. Revista de Estudos Curriculares, v. 9, n. 2, p. 20-33, 2019. 


\section{Como referenciar este artigo}

VOIGT, J. M. R.; HARACEMIV, S. M. C.; CAMARGO, N. M.; RATTI, L. A. Mudanças curriculares e formação docente: desafios e possibilidades. Revista Ibero-Americana de Estudos em Educação, Araraquara, v. 16, n. esp. 1, p. 835-849, mar. 2021. e-ISSN: 19825587. DOI: https://doi.org/10.21723/riaee.v16iEsp.1.14918

Submissão em: 20/06/2020

Revisões requeridas em: 16/09/2020

Aceito em: 03/11/2020

Publicado em: 01/03/2021 